\title{
RESEARCH
}

Open Access

\section{Opioid legislation and narcotic filling in total hip arthroplasty: descriptive study of time and state-level trends in the United States}

Daniel J. Cunningham ${ }^{1 *}$ (D), Sean P. Ryan ${ }^{1}$, Steven Z. George ${ }^{1,2}$ and Brian D. Lewis ${ }^{1}$

\begin{abstract}
Background: The opioid misuse epidemic focused national attention on reducing opioid overprescribing. The purpose of this study is to describe the relationship of time and state-level interventions and opioid filling surrounding total hip arthroplasty (THA) in the United States.

Methods: A national database with diverse insurance constituents was queried for first-prescription and cumulative perioperative opioid filling volumes and rates in oxycodone 5-mg equivalents (OE's) in 487,942 patients undergoing primary THA from 30-days pre-operative to 90-days post-operative. Descriptive statistics evaluated pre-legislative and post-legislative opioid filling by state, legislative type, and surgery year.

Results: At the national level, initial opioid filling volumes have remained largely unchanged (56.2 OE's in 2010 to 51.7 OE's in 2018). Meanwhile, cumulative opioid filling volumes (151.9 OE's in 2010 to 111.7 OE's in 2018) have decreased considerably. Rates of initial opioid prescriptions exceeding 90 OE's were similar in 2010 (6.4\%) and 2018 (5.6\%). States with legislation targeting duration and volume of opioid prescriptions saw the largest decreases in opioid prescription filling. That is, 75\% of states with opioid legislation had large (> 10 oxycodone 5 -mg equivalents) decreases in cumulative 90 -day opioid filling compared to only $20 \%$ of states without opioid legislation having large decreases in cumulative 90-day opioid filling.

Conclusions: This descriptive study demonstrates decreases in perioperative opioid filling for THA. Although this study was descriptive in nature, states enacting opioid-limiting legislation had larger decreases. Although causal relationships could not be inferred from this analysis, the results suggest that states without legislation could improve prescriber compliance with national goals of decreased opioid overprescribing by enacting opioid-limiting legislation.
\end{abstract}

Level of evidence: Level III, retrospective prognostic cohort study.

Keywords: Opioid, State legislation, Total hip arthroplasty

\footnotetext{
* Correspondence: Daniel.cunningham@duke.edu

'Department of Orthopaedic Surgery, Duke University Medical Center, 200

Trent Drive, Durham, NC 27710, USA

Full list of author information is available at the end of the article
}

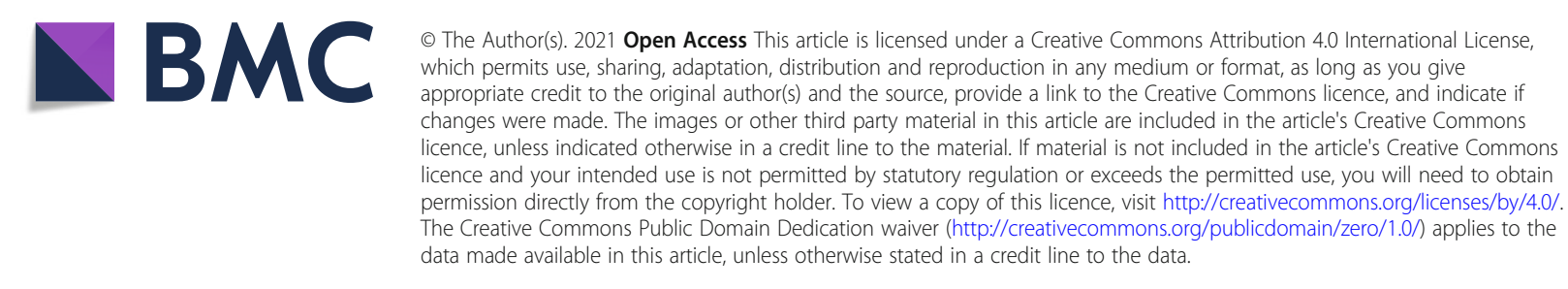




\section{Introduction}

Total hip arthroplasty (THA) is an invasive procedure, and despite excellent long-term outcomes and improvement in function, initial post-operative pain can be difficult to manage [1]. Throughout the 1990's there was a significant effort to focus on controlling patients' postoperative pain. In 1999, the California legislature mandated recording of patient's pain along with vital sign measurements [2]. This newfound focus on pain as a vital sign in the 2000's, in conjunction with research demonstrating that pain is one of the most important determinants of satisfaction following THA [3], led to widespread increased utilization of opioids in the perioperative period.

Opioids continue to be commonly used to control immediate post-operative pain. However, more recently, the opioid epidemic has garnered significant attention as the number of opioid related deaths and chronic opioid users continue to grow [4]. Amongst interventions leading to chronic opioid use, spine and orthopaedic procedures have stood out as the top two drivers for initial prescriptions that lead to sustained opioid use [5]. Thus, some legislators have made efforts to amend opioid prescribing practices and instituted maximum prescribing limits. For arthroplasty surgeons in particular, this has been an area of active research and discussion throughout the American Association of Hip and Knee Surgeons (AAHKS), in an effort to investigate and change opioid prescribing habits.

The purpose of this study is to describe the relationship of time and state-level interventions and opioid filling surrounding total hip arthroplasty (THA) in the United States.

\section{Method}

\section{Study design}

This was a descriptive study of perioperative opioid filling in patients undergoing primary total hip arthroplasty between 2010 and 2018 using a large, national database. This study was designed and reported in accordance with the Strengthening the Reporting of Observational Studies in Epidemiology (STROBE) statement on observational studies [6]. This study was approved by the institutional review board.

\section{Variables and data sources}

All patients ages 18 and older undergoing primary total hip arthroplasty were identified in the PearlDiver (PearlDiver, Inc.) Mariner dataset (see Additional file 1: Table S1 for codes used to identify primary total hip arthroplasty) and opioid filling trends evaluated from 30 -days pre-operative to 90 -days post-operative. This dataset includes information on 122 million distinct patients from 2010 to 2018 with a broad geographic and demographic variety of insurance coverage (Medicare, Medicaid, commercial, and cash-pay) in the United States. The database facilitates blinded longitudinal, patient-specific tracking of information available through International Classification of Disease (ICD)-9, ICD-10, and Current Procedural Terminology (CPT) codes. Importantly, this database keeps record of patients across states, providers, and care settings. Further, it includes information on all prescriptions filled at all pharmacies within the United States with exception of inpatient pharmacies. All opioids were included in this study with exception of opioids intended for cough suppression, which were identified by presence of alpha-agonists or anti-histamines. In line with recent recommendations on opioid-related database studies in orthopaedic surgery, this specific dataset was selected due to the granular, patient-level information that it provides on opioid filling [7]. Although this dataset provides users exceptional granularity, researchers are blinded to the data and are limited in statistical testing to preserve anonymity. For that reason, a descriptive approach was utilized. In order to select a cohort of patients with broad applicability to patients undergoing primary total hip arthroplasty for osteoarthritis, exclusion criteria included prior hip fracture diagnosis (see Additional file 1: Table S1 for codes used to exclude hip fracture) and patients with exceptionally high perioperative opioid demand (> 8000 morphine milliequivalents or 467 oxycodone 5-mg equivalents or OE's filled from 1-month pre-operative to 3 -months postoperative). The cohort included all patients with active insurance status from 6-months pre-op to 3-months post-op, $n=541,353$. The main study outcomes were the volume of opioids filled and rate of opioid filling and refills over the study timeframe. Filled prescriptions were converted from oral morphine equivalents (OME's) into oxycodone 5-mg equivalents (OE's) for ease of interpretation using conversion factors proposed by the Centers for Disease Control (CDC) [8]. Baseline patient and operative factors were recorded including age, sex, obesity (see Additional file 1: Table S1 for coding definition), Charlson comorbidity index (CCI), pre-operative (6-months to 1-month preoperative) opioid filling, year of surgery, and state of opioid prescription. Patients that filled opioid prescriptions within the 6-month to 1-month pre-operative window were dichotomized into patients with one versus two or more prescriptions. The patients with two or more prescriptions were considered to have chronic opioid use, similar to definitions used by the CDC. However, the 1-month pre-operative period was excluded since some patients may have received and filled an opioid prescription pre-operatively intended for post-operative usage [9]. 
Next, opioid prescribing legislation was reviewed for each state (see Additional file 2: Table S2, [10]). Some states limited opioid duration, volume, or both factors. Additionally, some states passed legislation that was specific to certain small subgroups of patients such as patients on Medicaid. In this analysis, only legislation that affected all state residents was considered. Legislation dates were determined for each state and opioid filling was evaluated before and after legislation. Some states have not enacted legislation. In this case, September 10, 2017 was used as the before/after date since it was the mean date of legislation passage in the cohort of states in which opioid legislation was passed. Lastly, yearspecific rates of initial prescriptions exceeding 90 OE's (675 MME's) were also evaluated to determine the relationship of time and outlier prescribing. 90 OE's was chosen to represent a "large" opioid prescription based on a prior study [11].

\section{Data analysis}

A descriptive approach was selected rather than an inferential approach. Trends were clear and statistical comparisons were not particularly useful in setting of the exceptionally large sample size. Further, advanced statistical testing such as multilevel modeling, which could address anticipated year-level and state-level clustering, is not available within the blinded dataset and statistical environment that PearlDiver offers. Baseline characteristics and outcomes were displayed with means (standard deviations), medians, or proportions (percentages) as appropriate. Unadjusted outcomes were calculated including mean OE's per filler and rates of one or more or two or more opioid prescriptions. Prescription filling data were broken down by year, legislation presence/absence, legislation type, and state to further analyze these factors.

\section{Funding}

There were no sources of funding for this study.

\section{Results}

Most patients were 65 and older (Table 1). Males comprised $43 \%$ of the population. $20 \%$ of patients were obese. $23.4 \%$ of patients filled two or more opioid prescriptions within the 6-month pre-operative to 1-month pre-operative timeframe. The median CCI was 0 , while the mean was 1.1. The distribution of patients across the 2010-2018 timeframe was even with consideration of fewer patients that were able to meet active insurance status at the end of the dataset's available timeframe (2018) and fewer patients available for analysis in 2010.

As shown in Table 2, initial opioid filling volume has not changed dramatically (56.2 OE's in 2010 to 51.7
Table 1 Baseline patient and operative characteristics

\begin{tabular}{|c|c|}
\hline $\begin{array}{l}\text { Baseline patient and operative } \\
\text { characteristics }\end{array}$ & $\begin{array}{l}\text { Study cohort }(n= \\
541,353)\end{array}$ \\
\hline \multicolumn{2}{|l|}{ Age } \\
\hline 18 to 19 years & $185(0 \%)$ \\
\hline 20 to 24 years & $713(0.1 \%)$ \\
\hline 25 to 29 years & $1274(0.2 \%)$ \\
\hline 30 to 34 years & $2149(0.4 \%)$ \\
\hline 35 to 39 years & $4214(0.8 \%)$ \\
\hline 40 to 44 years & $8927(1.6 \%)$ \\
\hline 45 to 49 years & $19,830(3.7 \%)$ \\
\hline 50 to 54 years & $41,043(7.6 \%)$ \\
\hline 55 to 59 years & $66,534(12.3 \%)$ \\
\hline 60 to 64 years & $85,568(15.8 \%)$ \\
\hline 65 to 69 years & $91,048(16.8 \%)$ \\
\hline 70 to 74 years & $122,581(22.6 \%)$ \\
\hline 75 to 79 years & $93,717(17.3 \%)$ \\
\hline 80 to 84 years & $3570(0.7 \%)$ \\
\hline Male sex & $234,875(43.4 \%)$ \\
\hline Obesity & $109,291(20.2 \%)$ \\
\hline \multicolumn{2}{|l|}{ Pre-operative opioid use } \\
\hline One pre-op opioid prescription & $79,174(14.6 \%)$ \\
\hline Two or more pre-op opioid prescriptions & $126,792(23.4 \%)$ \\
\hline \multicolumn{2}{|l|}{ Charlson comorbidity index } \\
\hline $\mathrm{CCl} 0$ & $289,815(53.5 \%)$ \\
\hline $\mathrm{CCl} 1$ & $109,118(20.2 \%)$ \\
\hline $\mathrm{CCl} 2$ & $62,630(11.6 \%)$ \\
\hline $\mathrm{CCl} 3$ & $34,447(6.4 \%)$ \\
\hline $\mathrm{CCl} 4$ & $17,597(3.3 \%)$ \\
\hline CCl 5 or more & $27,746(5.1 \%)$ \\
\hline Mean CCI (SD) & $1.1(1.77)$ \\
\hline \multicolumn{2}{|l|}{ Year } \\
\hline 2010 & $21,718(4 \%)$ \\
\hline 2011 & $61,833(11.4 \%)$ \\
\hline 2012 & 66,077 (12.2\%) \\
\hline 2013 & 70,591 (13\%) \\
\hline 2014 & 75,123 (13.9\%) \\
\hline 2015 & 74,112 (13.7\%) \\
\hline 2016 & $73,574(13.6 \%)$ \\
\hline 2017 & 69,798 (12.9\%) \\
\hline 2018 & $28,514(5.3 \%)$ \\
\hline
\end{tabular}

OE's in 2018). However, the overall cumulative (151.9 OE's in 2010 to 111.7 OE's in 2018) opioid filing volume has decreased $26 \%$ since 2010 . This drop appeared to be most dramatic between 2016 and 2018. Rates of initial 
Table 2 Year-specific opioid filling volumes and rates across the entire study cohort in oxycodone 5-mg equivalents. Mean (standard deviation) or sample size and percentage displayed

\begin{tabular}{llllll}
\hline Timeframe & $\begin{array}{l}\text { Oxycodone 5-mg equiva- } \\
\text { lents (first prescription) }\end{array}$ & $\begin{array}{l}\text { Oxycodone 5-mg equiva- } \\
\text { lents (cumulative) }\end{array}$ & $\begin{array}{l}\mathbf{1} \text { or more opioid } \\
\text { prescriptions }\end{array}$ & $\begin{array}{l}\mathbf{2} \text { or more opioid } \\
\text { prescriptions }\end{array}$ & $\begin{array}{l}\text { Initial volume } \mathbf{9 0} \\
\text { oxycodone 5-mg } \\
\text { equivalents }\end{array}$ \\
\hline 2010 & $56.2(38.9)$ & $151.9(105.3)$ & $12,917(59.5 \%)$ & $8171(37.6 \%)$ & $1387(6.4 \%)$ \\
2011 & $55.8(38.7)$ & $141.8(105.7)$ & $39,590(64 \%)$ & $26,208(42.4 \%)$ & $4319(7 \%)$ \\
2012 & $56.8(38.6)$ & $140.8(104.9)$ & $42,277(64 \%)$ & $27,684(41.9 \%)$ & $4901(7.4 \%)$ \\
2013 & $57.5(38.3)$ & $140.2(104.5)$ & $46,734(66.2 \%)$ & $30,102(42.6 \%)$ & $5666(8 \%)$ \\
2014 & $58.7(38.8)$ & $139.8(102.4)$ & $50,784(67.6 \%)$ & $32,575(43.4 \%)$ & $6508(8.7 \%)$ \\
2015 & $62.2(39.9)$ & $140.4(101)$ & $50,271(67.8 \%)$ & $31,286(42.2 \%)$ & $7622(10.3 \%)$ \\
2016 & $61.5(39.6)$ & $136.8(99.7)$ & $51,373(69.8 \%)$ & $31,429(42.7 \%)$ & $7311(9.9 \%)$ \\
2017 & $57.7(37.3)$ & $126.5(96.1)$ & $49,009(70.2 \%)$ & $29,448(42.2 \%)$ & $5619(8.1 \%)$ \\
2018 & $51.7(33.9)$ & $111.7(91.3)$ & $19,943(69.9 \%)$ & $11,484(40.3 \%)$ & $1590(5.6 \%)$ \\
\hline
\end{tabular}

opioid prescription volume exceeding 90 oxycodone 5mg equivalents increased from 2010 (6.4\%) to 2015 (10.3\%) and then decreased to 2018 (5.6\%).

When compiling states with and without legislation and evaluating initial and cumulative opioid prescriptions pre-act and post-act, states with and without legislation have had reductions in opioid filling. However, states with legislation had larger magnitude of reductions in both initial and cumulative filling volume (Table 3) compared to states without legislation (9.8 vs 1.3 initial and 33.8 vs 16.8 cumulative OE's).

States with legislation targeting duration and volume had the largest reductions in pre-act to post-act opioid filling volume (Table 4). Figures 1 and 2 show a heat map of initial and cumulative opioid filling volume before and after legislation for specific states. Appendix Figures 3 and 4 show year-level changes in state-specific opioid legislation.

Table 5 demonstrates reductions in pre-act to post-act initial and cumulative opioid filling volumes. With regard to initial prescription filling volume, differences were largest in Arizona, Hawaii, Massachusetts,

Table 3 Pre-act and post-act initial and cumulative opioid filling in oxycodone 5-mg equivalents in states with and without legislation. Mean (standard deviation, sample size) displayed

\begin{tabular}{|c|c|c|}
\hline Pooled states & Pre-act & Post-act \\
\hline \multicolumn{3}{|l|}{ Initial prescription } \\
\hline With legislation & $59.6(39.3 ; n=251,007)$ & $50.1(31.9 ; n=29,261)$ \\
\hline Without legislation & $58.1(38.7 ; n=60,614)$ & $56.8(37.3 ; n=5024)$ \\
\hline \multicolumn{3}{|l|}{ Cumulative prescriptions } \\
\hline With legislation & $140.2(103.1 ; n=373,988)$ & $106.4(87.9 ; n=42,113)$ \\
\hline Without legislation & $142.5(103.6 ; n=93,674)$ & $125.7(96 ; n=7297)$ \\
\hline
\end{tabular}

Michigan, North Carolina, New York, Ohio, and Rhode Island (exceeding 10 oxycodone 5-mg equivalents). Meanwhile, while there were large reductions in cumulative opioid filling volume for many states. Notably, Arizona and New Hampshire each had reductions greater than 40 OE's.

\section{Discussion}

This descriptive study reports perioperative opioid filling volume and rates of opioid filling and refills after primary, THA in a large, commercially available insurance database from 2010 to 2018 . The purpose of the study was to describe the relationship of time and opioidrelated legislation on perioperative opioid filling. In doing so we reported general trends of opioid prescription, including identifying potential variation by state level legislations. Specifically, cumulative (152 OE's in 2010 to 112 OE's in 2018) opioid filling volume has decreased since 2010 while initial opioid filling volume (56 OE's in 2010 to 52 OE's in 2018) and the rate of initial opioid filling volume exceeding 90 OE's (6.4\% in 2010 and $5.6 \%$ in 2018) has remained largely unchanged. States with legislation targeting opioid prescription duration and volume had the largest decreases in initial and cumulative opioid prescription filling. This was a descriptive study so while these findings are compelling, they should primarily be used to generate hypotheses for future study of this important topic.

Due to the growing attention around the opioid epidemic and evidence suggesting that orthopaedic procedures may contribute to chronic opioid use, research on perioperative opioids around THA has become increasingly common [2]. Delaney et al. demonstrated that for opioid naïve patients 65 years of age or greater undergoing THA, high initial opioid prescriptions were correlated with prolonged opioid use [12], and Hannon et al. 
Table 4 Initial and 90-day post-operative cumulative opioid filling volume in pre-act and post-act legislation cohorts by legislation type in oxycodone 5-mg equivalents. Means and standard deviations displayed

\begin{tabular}{|c|c|c|}
\hline Legislation type & Pre-act & Post-act \\
\hline \multicolumn{3}{|l|}{ Initial } \\
\hline No legislation & $58.1(38.7 ; n=60,614)$ & $56.8(37.3 ; n=5024)$ \\
\hline Duration & $59.6(39.7 ; n=187,681)$ & $50.7(32.1 ; n=22,757)$ \\
\hline Volume & $58.9(37.7 ; n=6763)$ & $54.8(34.3 ; n=699)$ \\
\hline Duration and volume & $58.9(38 ; n=35,602)$ & $46.1(29.8 ; n=4638)$ \\
\hline No specified duration or volume & $60.1(39.1 ; n=20,961)$ & $51.7(31.8 ; n=1167)$ \\
\hline \multicolumn{3}{|l|}{ Cumulative } \\
\hline No legislation & $142.5(103.6 ; n=93,674)$ & $125.7(96 ; n=7297)$ \\
\hline Duration & $139.9(103.3 ; n=278,282)$ & $106.7(87.3 ; n=32,772)$ \\
\hline Volume & $139.6(102.2 ; n=10,779)$ & $113(92 ; n=1040)$ \\
\hline Duration and volume & $142.6(103.4 ; n=51,505)$ & $103(89.8 ; n=6531)$ \\
\hline No specified duration or volume & $138.8(100.7 ; n=33,422)$ & $109.9(89.7 ; n=1770)$ \\
\hline
\end{tabular}

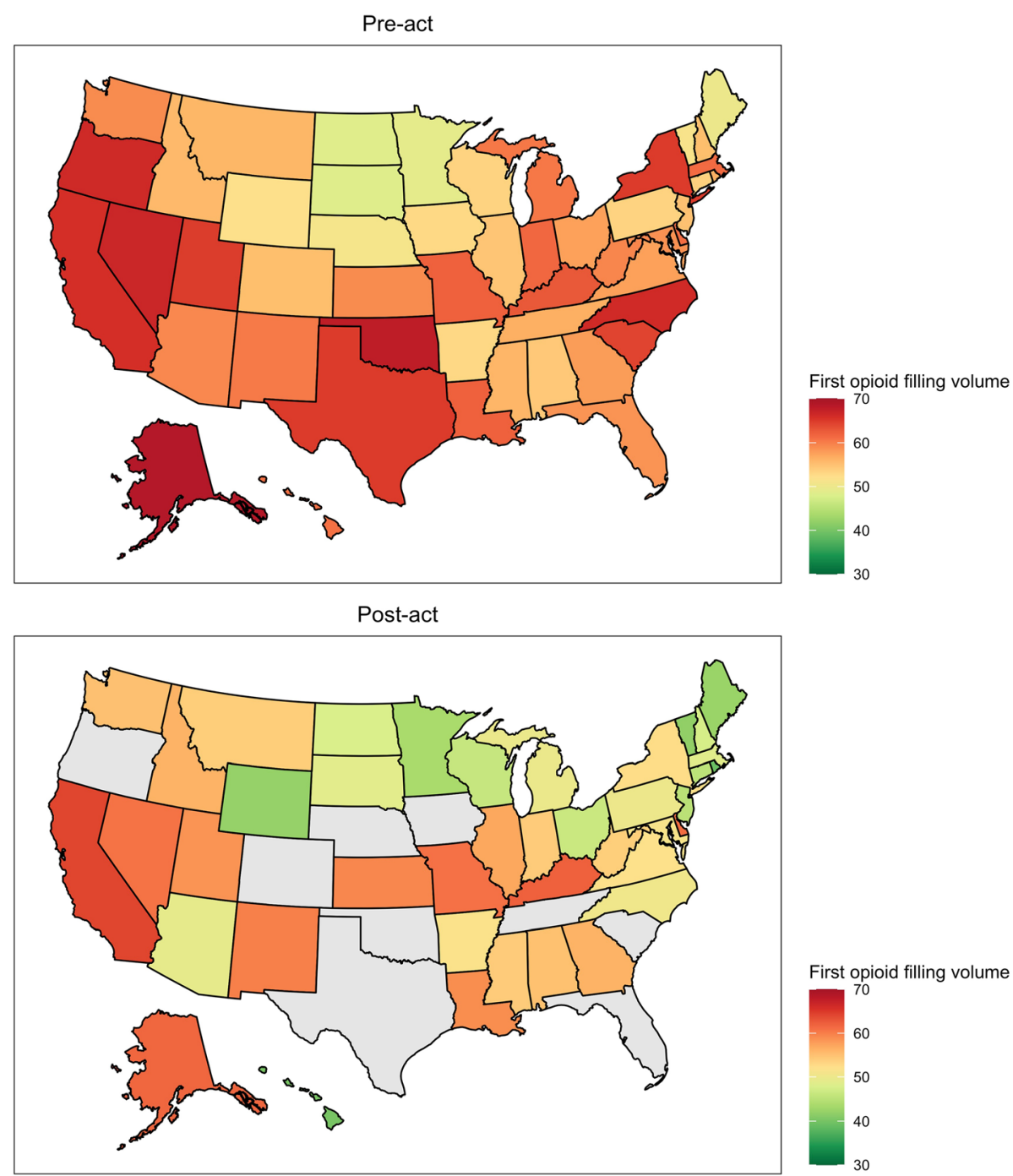

Fig. 1 First opioid prescription volume pre-act and post-act heat map. States in grey had insufficient data post-act to display. For states without legislation, 9/10/2017 was used as the act date 


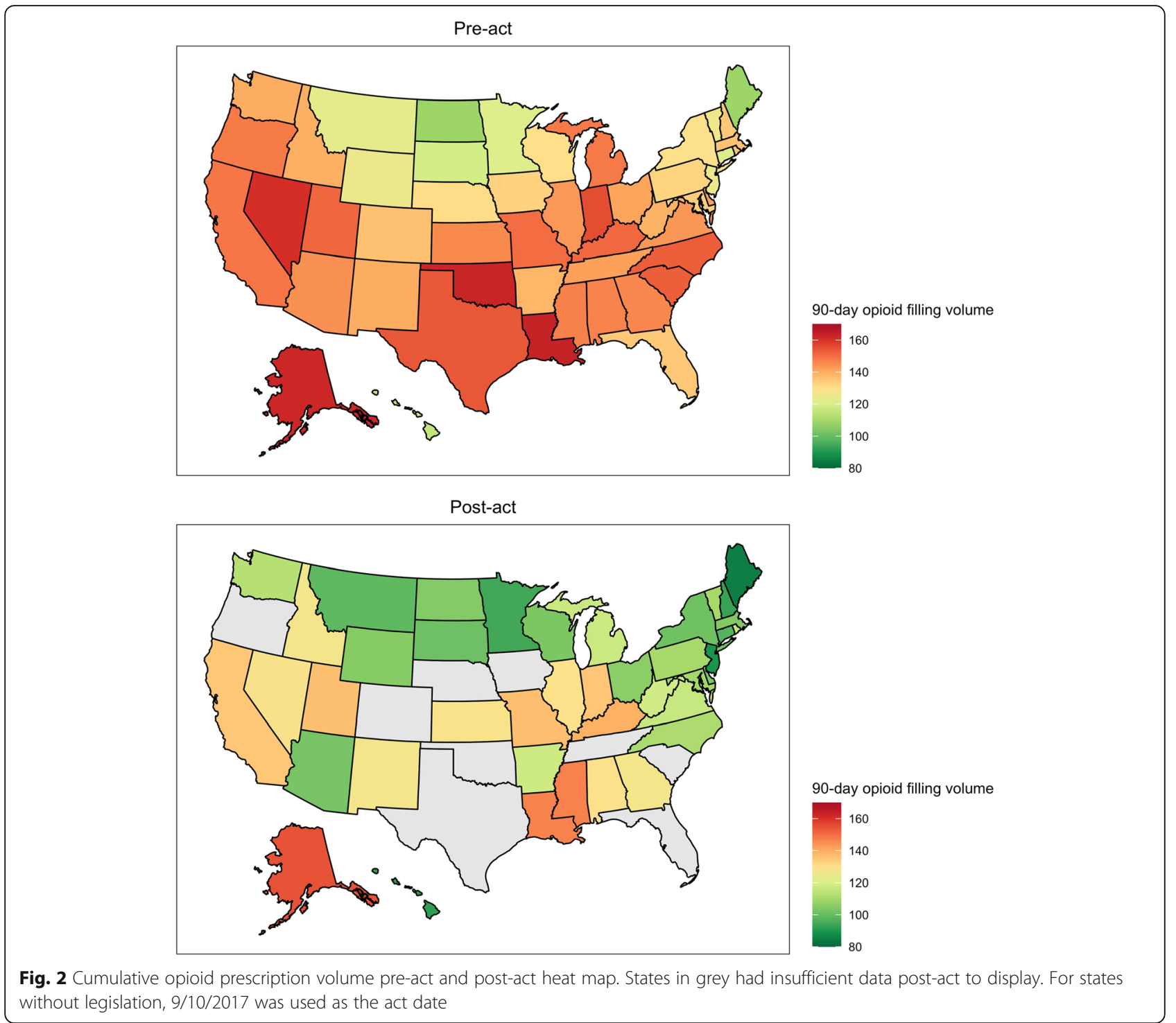

showed that when more tablets are prescribed, it was independently associated with greater consumption, despite no differences in pain scores or patient reported outcomes measures [11]. This is important, because several authors have demonstrated that institutional protocols for prescribing can directly lead to a reduction in opioid consumption [13-15]. Still, however, the optimum number of narcotic tablets to prescribe at discharge is multifactorial and likely influenced by individual institution's multimodal analgesia protocols, patient factors, and surgeon and hospital experience. Runner et al., in a prospective cohort study, demonstrated that the average number of days taking narcotic analgesia was 8.5, with an average of 20.8 pills taken during that time (despite 72.5 pills prescribed) [16]. In a recent survey of AAHKS members, the average number of narcotics tablets prescribed was 44 (range 0-200) at discharge from THA, with $74 \%$ of respondents utilizing multimodal analgesia [17]. Indeed, there remains significant variability in opioid prescribing after THA, with higher tablet volumes coming from providers with fewer years in practice and who had higher volume practices [18].

In part, based on the growing body of evidence demonstrating perioperative opioid use as contributing to prolonged narcotics use, individual State and the Federal government have passed opioid legislation [19] enacting prescribing limits, clinical guidelines, prescription drug monitoring programs, mandated continuing education, and recovery centers. Rhode Island law to reduce opioid 
Table 5 1-month pre-operative to 90-days post-operative initial and cumulative prescription opioid filling volume by state in oxycodone 5-mg equivalents. States with no opioid legislation were included for comparison. The mean date of legislation (9/10/ 2017) was used for states without opioid legislation. Mean (standard deviation, sample size) displayed. Sample sizes for initial opioid filling volume only include patients with at least one filled opioid prescription during the timeframe

\begin{tabular}{|c|c|c|c|c|c|c|}
\hline State & Pre-act initial & Post-act initial & Initial difference & Pre-act cumulative & Post-act cumulative & Cumulative difference \\
\hline \multicolumn{7}{|c|}{ Duration } \\
\hline KY & $62.9(41.1 ; n=4726)$ & $62.3(39.5 ; n=751)$ & 0.7 & $151(108.5 ; n=6942)$ & $139.8(104.8 ; n=1094)$ & 11.2 \\
\hline MN & $49(31.6 ; n=5400)$ & $43.9(28 ; n=901)$ & 5.1 & $121.3(96.7 ; n=10,543)$ & $94.5(80.9 ; n=1607)$ & 26.7 \\
\hline$A Z$ & $59.4(37.7 ; n=7225)$ & $49.3(31.6 ; n=251)$ & 10.1 & $144.6(106.5 ; n=10,019)$ & $102.4(83.8 ; n=355)$ & 42.1 \\
\hline NJ & $55.1(36 ; n=11,955)$ & $45.4(27.5 ; n=2470)$ & 9.7 & $124.5(95.7 ; n=18,023)$ & $89.9(75.1 ; n=3541)$ & 34.6 \\
\hline AK & $68.8(42 ; n=564)$ & $61.7(42.9 ; n=55)$ & 7.1 & $162.1(108.1 ; n=804)$ & $154.6(113.3 ; n=79)$ & 7.4 \\
\hline $\mathrm{CT}$ & $53.8(35.1 ; n=5103)$ & $45.6(26.5 ; n=1817)$ & 8.2 & $121.1(93.7 ; n=8447)$ & $97.5(81.1 ; n=2756)$ & 23.6 \\
\hline $\mathrm{DE}$ & $61.2(38.3 ; n=2143)$ & $61.5(32.3 ; n=379)$ & -0.3 & $141.6(100.6 ; n=2821)$ & $104(80.4 ; n=499)$ & 37.6 \\
\hline $\mathrm{HI}$ & $60.8(39.9 ; n=565)$ & $40.2(35.4 ; n=72)$ & 20.6 & $115.8(89.2 ; n=990)$ & $91.8(96.9 ; n=111)$ & 24 \\
\hline IN & $61.8(41.3 ; n=8802)$ & $54.4(33.8 ; n=918)$ & 7.4 & $155.4(109 ; n=11,731)$ & $135.2(98.8 ; n=1229)$ & 20.2 \\
\hline LA & $62.4(41.2 ; n=2912)$ & $59.1(37.1 ; n=366)$ & 3.3 & $163.7(111.7 ; n=3924)$ & $146.8(108.9 ; n=468)$ & 16.9 \\
\hline MA & $61.5(37.5 ; n=4644)$ & $48.9(31.1 ; n=1846)$ & 12.6 & $136.1(98.9 ; n=6875)$ & $104.5(86.8 ; n=2586)$ & 31.6 \\
\hline $\mathrm{Ml}$ & $60.6(38.5 ; n=16,155)$ & $50(31 ; n=1035)$ & 10.5 & $148.2(107.3 ; n=23,048)$ & $117.4(91.6 ; n=1385)$ & 30.8 \\
\hline NC & $66.4(43 ; n=7591)$ & $50.5(29.9 ; n=277)$ & 15.9 & $152.7(104.8 ; n=11,605)$ & $111.1(87.7 ; n=418)$ & 41.6 \\
\hline $\mathrm{NH}$ & $55.3(33.8 ; n=1072)$ & $47.6(27 ; n=274)$ & 7.8 & $134.7(96.7 ; n=1450)$ & $93.1(75.7 ; n=369)$ & 41.6 \\
\hline NY & $65(43.5 ; n=16,052)$ & $52.8(34.3 ; n=5847)$ & 12.2 & $129.9(98 ; n=25,301)$ & $101.5(83.6 ; n=8430)$ & 28.4 \\
\hline PA & $53.5(36.2 ; n=14,895)$ & $50.3(31.8 ; n=4099)$ & 3.2 & $132.4(100.5 ; n=22,882)$ & $110.2(87.8 ; n=5739)$ & 22.2 \\
\hline UT & $65(42 ; n=1415)$ & $59.4(32.7 ; n=145)$ & 5.6 & $151.2(106.6 ; n=2263)$ & $136.4(97.5 ; n=213)$ & 14.8 \\
\hline VA & $57.7(38.3 ; n=5826)$ & $52(32.2 ; n=1224)$ & 5.7 & $143.8(103 ; n=8585)$ & $116.2(91.4 ; n=1832)$ & 27.5 \\
\hline W & $59.6(38.1 ; n=2636)$ & $53.8(33.1 ; n=28)$ & 5.8 & $138.9(104.2 ; n=3794)$ & $118.5(89.9 ; n=55)$ & 20.5 \\
\hline \multicolumn{7}{|c|}{ Volume } \\
\hline VT & $51.5(27.3 ; n=237)$ & $41.8(22 ; n=21)$ & 9.7 & $125.4(86.9 ; n=405)$ & $110(113.2 ; n=38)$ & 15.4 \\
\hline WA & $59.2(38 ; n=6526)$ & $55.2(34.5 ; n=678)$ & 4 & $140.2(102.7 ; n=10,374)$ & $113(91.3 ; n=1002)$ & 27.1 \\
\hline \multicolumn{7}{|c|}{ Duration and volume } \\
\hline $\mathrm{OH}$ & $57.7(37 ; n=24,998)$ & $46.6(29.3 ; n=2646)$ & 11.1 & $141.4(102.5 ; n=36,003)$ & $105.8(88.9 ; n=3763)$ & 35.6 \\
\hline $\mathrm{Rl}$ & $56.7(34.1 ; n=970)$ & $39.6(29.6 ; n=421)$ & 17.1 & $135.6(98.5 ; n=1407)$ & $116.2(105.3 ; n=574)$ & 19.5 \\
\hline NV & $66.9(46.2 ; n=2756)$ & $60.7(37.7 ; n=367)$ & 6.2 & $160.5(110 ; n=3752)$ & $128(96 ; n=483)$ & 32.5 \\
\hline ME & $50.1(31.4 ; n=1874)$ & $42.6(26.7 ; n=1204)$ & 7.4 & $108.6(92 ; n=3135)$ & $84.7(80 ; n=1710)$ & 23.9 \\
\hline \multicolumn{7}{|c|}{ No specific duration or amount } \\
\hline $\mathrm{MD}$ & $58.8(38.1 ; n=7721)$ & $51.7(31.8 ; n=1167)$ & 7.1 & $133.9(99.5 ; n=11,978)$ & $109.9(89.7 ; n=1768)$ & 24 \\
\hline \multicolumn{7}{|c|}{ No legislation } \\
\hline $\mathrm{AL}$ & $54.4(38 ; n=2898)$ & $55.4(33.5 ; n=315)$ & -1 & $146.5(110.6 ; n=4109)$ & $130.3(100.1 ; n=415)$ & 16.2 \\
\hline$A R$ & $53.1(37.3 ; n=1688)$ & $51.8(36.6 ; n=173)$ & 1.3 & $138.3(107.9 ; n=2546)$ & $117.6(99.9 ; n=231)$ & 20.7 \\
\hline CA & $65.9(43 ; n=12,892)$ & $64.5(39.9 ; n=1013)$ & 1.4 & $148.6(106.7 ; n=21,706)$ & $135.4(101.2 ; n=1661)$ & 13.1 \\
\hline DC & $49.7(28 ; n=473)$ & $52.4(56 ; n=49)$ & -2.8 & $120.3(92.6 ; n=733)$ & $108.9(101.1 ; n=74)$ & 11.4 \\
\hline GA & $58.1(36.7 ; n=10,808)$ & $56.4(38.2 ; n=699)$ & 1.7 & $145.9(103.1 ; n=14,847)$ & $126.8(94.9 ; n=974)$ & 19.1 \\
\hline $\mathrm{ID}$ & $55.9(36.3 ; n=774)$ & $56.2(41.5 ; n=83)$ & -0.4 & $140(101.4 ; n=1299)$ & $126.6(96.7 ; n=119)$ & 13.4 \\
\hline $\mathrm{IL}$ & $54.7(37.4 ; n=11,995)$ & $57.1(39.8 ; n=969)$ & -2.4 & $143.3(103.6 ; n=17,967)$ & $129.6(96 ; n=1377)$ & 13.7 \\
\hline KS & $59.1(37.7 ; n=2143)$ & $59.4(36.8 ; n=184)$ & -0.3 & $145.8(103.2 ; n=3183)$ & $128.3(100.9 ; n=255)$ & 17.5 \\
\hline MO & $62.2(42.4 ; n=4561)$ & $61.1(35.5 ; n=405)$ & 1.1 & $150.1(104.8 ; n=6727)$ & $136.7(96.1 ; n=554)$ & 13.4 \\
\hline MS & $56.3(38.1 ; n=1373)$ & $54.1(39 ; n=105)$ & 2.2 & $147.2(105.5 ; n=2062)$ & $147(118.2 ; n=164)$ & 0.2 \\
\hline MT & $56(338 \cdot n=823)$ & $54(30 \cdot n=74)$ & 2 & $1231(964 \cdot n=1378)$ & $988(615 \cdot n=120)$ & 243 \\
\hline
\end{tabular}


Table 5 1-month pre-operative to 90-days post-operative initial and cumulative prescription opioid filling volume by state in oxycodone 5-mg equivalents. States with no opioid legislation were included for comparison. The mean date of legislation (9/10/ 2017) was used for states without opioid legislation. Mean (standard deviation, sample size) displayed. Sample sizes for initial opioid filling volume only include patients with at least one filled opioid prescription during the timeframe (Continued)

\begin{tabular}{rllllll}
\hline State & Pre-act initial & Post-act initial & Initial difference & Pre-act cumulative & Post-act cumulative & Cumulative difference \\
\hline ND & $48.6(29.4 ; n=853)$ & $47.8(31 ; n=98)$ & 0.8 & $108.6(85.8 ; n=1396)$ & $104.5(78.5 ; n=124)$ & 4.1 \\
NM & $60.6(38.4 ; n=1014)$ & $60(41 ; n=110)$ & 0.6 & $139.8(102.8 ; n=1518)$ & $126.8(95.6 ; n=141)$ & 13 \\
SD & $48.4(30.8 ; n=1070)$ & $49.1(32.8 ; n=168)$ & -0.7 & $118.8(88.3 ; n=1797)$ & $101.2(76.8 ; n=230)$ & 17.6 \\
WI & $53.4(34.5 ; n=6770)$ & $46.1(24.5 ; n=531)$ & 7.3 & $130.2(97.1 ; n=11,673)$ & $103.5(83.5 ; n=793)$ & 26.8 \\
WY & $52.3(41.8 ; n=479)$ & $43(23.3 ; n=48)$ & 9.3 & $125.1(98.4 ; n=733)$ & $107.1(82.9 ; n=65)$ & 17.9 \\
\hline
\end{tabular}

prescribing was passed in 2016, which limited opioid naïve patients to 30 morphine milligram equivalents per day or 20 doses post-operatively [20]. Studies in other subspecialties such as hand surgery and sports medicine have demonstrated surprising disconnects between the volume of opioid prescribed and consumed [21-23]. Reid et al. demonstrated that for opioid naïve patients undergoing arthroplasty, cumulative postoperative prescriptions were significantly decreased following enactment [20].

Our results demonstrate state-by-state variability with opioid prescribing. This study adds depth and breadth to the findings of Sabatino et al., which suggested large intra-institutional variability in opioid filling across a variety of elective orthopaedic procedures [24]. Given the growing body of legislation, the considerable down-trend in filling seen in 2016-2018 (cumulative perioperative opioid filling) across the nation may be the inflection point the opioid overprescribing epidemic has been waiting for. It is also important to recognize that states without opioidlimiting legislation have had decreases in prescription filling volumes. While impossible to prove with this dataset, the authors speculate that these reductions are related to increased social awareness of the dangers of opioids.

There are several notable limitations to this study. First, we utilized a large national database and are unable to review individual patient charts. However, in order to evaluate national opioid trends, we feel this is appropriate. Furthermore, the PearDiver database includes private insurance claims as well as Medicare, thus allowing analysis of a large patient cohort to identify subtle data trends. Second, we are unable to know the indications for opioid prescribing. It is possible that patients received opioid prescriptions for indications unrelated to their THA. We anticipate that this effect is small in the perioperative timeframe, however. Third, we do not have data on opioid consumption or opioid prescribing and are only able to report on opioid filling. While opioid consumption data would be ideal, opioid filling still may be a more accurate metric of opioid demand than opioid prescribing, as prescribing likely reflects prescriber practices to a greater degree than opioid filling. Interestingly, there was a high rate of opioid refills (43.9\%) in this patient population. However, these numbers are similar to the rate reported by Sabatino et al. in their study of prescribing patterns after THA. This analysis is also limited to 2010-2018 since these are the dates available for analysis in the most updated version of PearlDiver. It would be ideal to evaluate trends prior to 2010 as prescription filling has likely changed over a longer period of time than 2010-2018. Nonetheless, the earliest state-wide opioid-limiting legislation was enacted in 2016, which is well captured in this study. Lastly, we are unable to neatly separate the inter-related influence of national paradigm shifts in opioid prescription patterns from state-specific legislation. However, our analyses suggest that states with legislation have decreased filling volumes compared to states without legislation. Specifically, states mandating duration and volume limits had the largest decreases in opioid prescribing.

\section{Conclusions}

In conclusion, opioid filling after primary THA has decreased considerably in the United States since 2010. This descriptive study suggests part of this decrease could be related to opioid-specific state legislation. Although definitive conclusions cannot be drawn from these analyses, our finding suggest that states without opioid legislation may benefit from opioid legislation to decrease opioid overprescribing. These descriptive data also could be used to generate hypotheses for future studies that use more rigorous designs to determine the effect of policy and opioid prescription. 


\section{Appendix}

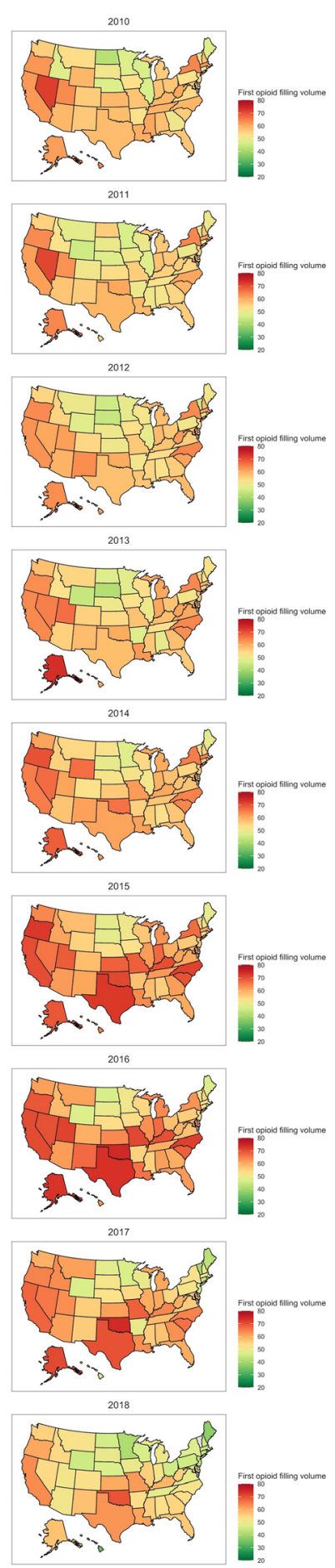

Fig. 3 State-level initial prescription oxycodone 5-mg equivalent filling volume from 2010 to 2018
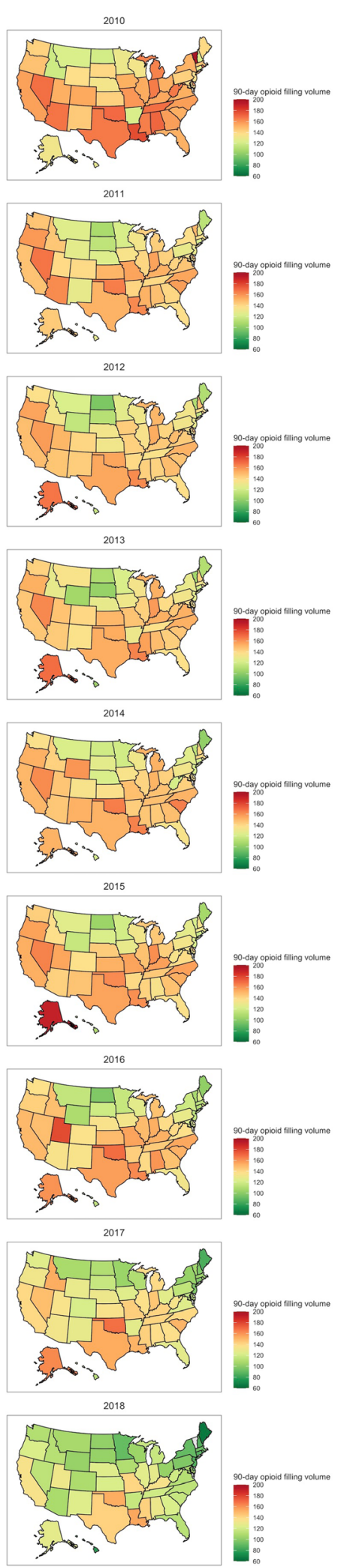

Fig. 4 State-level 90-day cumulative prescription oxycodone 5-mg equivalent filling volume from 2010 to 2018 


\section{Abbreviations}

THA: total hip arthroplasty; AAHKS: American Association of Hip and Knee Surgeons; STROBE: Strengthening the Reporting of Observational Studies in Epidemiology; CCl: Charlson comorbidity index; CDC: Centers for Disease Control; MME: morphine milligram equivalents; 30PRE-90POST: 1-month preoperative to 3-months post-operative time period; ANOVA: analysis of variance; OE: oxycodone 5-mg equivalent; CPT: Current Procedural Terminology; ICD: International Classification of Diseases

\section{Supplementary Information}

The online version contains supplementary material available at https://doi. org/10.1186/s13011-021-00410-w.

Additional file 1: Table S1. CPT, ICD-9, and ICD-10 code ranges used to identify patient cohorts.

Additional file 2: Table S2. Opioid legislation types and enactment dates for each state. The mean date of legislation (9/10/2017) was used for states without opioid legislation.

\section{Acknowledgements}

Not applicable.

\section{Authors' contributions}

DJC contributed to study design, analysis, and manuscript preparation; SPR contributed to manuscript preparation; SZG contributed to analysis and manuscript preparation; BDL contributed to analysis and manuscript preparation.

\section{Authors' information}

Not applicable

\section{Funding}

There were no sources of funding.

\section{Availability of data and materials}

The data that support the findings of this study are available from PearlDiver, Inc. but restrictions apply to the availability of these data, which were used under license for the current study, and so are not publicly available. Data are however available from the authors upon reasonable request and with permission of PearlDiver, Inc.

\section{Declarations}

\section{Ethics approval and consent to participate}

this study was reviewed by the local institutional review board and found to be exempt due to the retrospective observational nature of the study within the confines of an insurance database.

\section{Consent for publication}

not applicable.

\section{Competing interests}

The authors declare that they have no competing interests.

\section{Author details}

${ }^{1}$ Department of Orthopaedic Surgery, Duke University Medical Center, 200 Trent Drive, Durham, NC 27710, USA. ²Duke Clinical Research Institute, 200 Morris Street, Durham, NC 27701, USA.

\section{Accepted: 9 September 2021}

Published online: 28 September 2021

\section{References}

1. Bober K, Kadado A, Charters M, Ayoola A, North T. Pain control after total hip arthroplasty: a randomized controlled trial determining efficacy of fascia iliaca compartment blocks in the immediate postoperative period. J Arthroplasty. 2020;35(6S):S241.

2. Trasolini NA, MCKnight BM, Dorr LD. The Opioid Crisis and the Orthopedic Surgeon. J Arthroplasty. 2018;33(11):3379.
3. Brokelman RB, van Loon CJ, Rijnberg WJ. Patient versus surgeon satisfaction after total hip arthroplasty. J Bone Joint Surg Br. 2003;85(4):495.

4. Scholl L, Seth P, Kariisa M, Wilson N, Baldwin G. Drug and opioid-involved overdose deaths - United States, 2013-2017. MMWR Morb Mortal Wkly Rep. 2018;67(5152):1419.

5. Schoenfeld AJ, Jiang W, Chaudhary MA, Scully RE, Koehlmoos T, Haider AH. Sustained prescription opioid use among previously opioid-naive patients insured through TRICARE (2006-2014). JAMA Surg. 2017;152(12):1175.

6. von Elm E, Altman DG, Egger M, Pocock SJ, Gotzsche PC, Vandenbroucke $J P$, et al. The Strengthening the Reporting of Observational Studies in Epidemiology (STROBE) Statement: guidelines for reporting observational studies. Int J Surg. 2014;12(12):1495.

7. Bedard NA, Schoenfeld AJ, Kim SC, Large Database Research Discussion G. Optimum designs for large database research in musculoskeletal pain management. J Bone Joint Surg Am. 2020;102(Suppl 1):S54.

8. CDC compilation of benzodiazepines, muscle relaxants, stimulants, zolpidem, and opioid analgesics with oral morphine milligram equivalent conversion factors. In. National Center for Injury Prevention and Control: Centers for Disease Control and Prevention. 2019

9. Definitions Relevant to the Clinical QI Opioid Measures. In. Centers for Disease Control and Prevention. 2020

10. Opioid prescription limits and policies by state. 2020. https://ballotpedia. org/Opioid_prescription_limits_and_policies_by_state.

11. Hannon CP, Calkins TE, Li J, Culvern C, Darrith B, Nam D, et al. Rand young investigator's award: large opioid prescriptions are unnecessary after total joint arthroplasty: a randomized controlled trial. J Arthroplasty. 2019;34(7S):S4.

12. Delaney LD, Gunaseelan V, Rieck H, Dupree JM, Hallstrom BR, Waljee JF. High-risk prescribing increases rates of new persistent opioid use in total hip arthroplasty patients. J Arthroplasty. 2020;35(9):2472.

13. Wyles CC, Hevesi M, Trousdale ER, Ubl DS, Gazelka HM, Habermann EB, et al. The 2018 Chitranjan S. Ranawat, MD Award: developing and implementing a novel institutional guideline strategy reduced postoperative opioid prescribing after TKA and THA. Clin Orthop Relat Res. 2019;477(1):104.

14. Vaz KM, Huang PS, Copp SN. Standardized opioid prescription protocol reduces opioid consumption after total joint arthroplasty. J Am Acad Orthop Surg Glob Res Rev. 2019;3(12).

15. Holte AJ, Carender CN, Noiseux NO, Otero JE, Brown TS. Restrictive opioid prescribing protocols following total hip arthroplasty and total knee arthroplasty are safe and effective. J Arthroplasty. 2019;34(7S):S135.

16. Runner RP, Luu AN, Thielen ZP, Scudday TS, Nassif NA, Patel JJ, et al. Opioid use after discharge following primary unilateral total hip arthroplasty: how much are we overprescribing? J Arthroplasty. 2020;35(6S):S226.

17. Hannon CP, Keating TC, Lange JK, Ricciardi BF, Waddell BS, Della Valle CJ. Anesthesia and analgesia practices in total joint arthroplasty: a survey of the American Association of Hip and Knee Surgeons Membership. J Arthroplasty. 2019;34(12):2872.

18. Lipof JS, Thirukumaran CP, Greenstein AS, Zmich Z, Lander A, Ricciardi BF. Postdischarge opiate-prescribing habits for primary THA and TKA: a survey of American Association of Hip And Knee Surgeons Members. Orthopedics. 2019;42(6):361.

19. Webster LR, Grabois M. Current regulations related to opioid prescribing. PM R. 2015;7(11 Suppl):S236.

20. Reid DBC, Shapiro B, Shah KN, Ruddell JH, Cohen EM, Akelman E, et al. Has a prescription-limiting law in rhode island helped to reduce opioid use after total joint arthroplasty? Clin Orthop Relat Res. 2020;478(2):205.

21. Cunningham D, Lewis B, Hutyra C, Nho S, Olson S, Mather R. Prospective, observational study of opioid use after hip arthroscopy for femoroacetabular impingement syndrome. Arthroscopy. 2018;34(5):1488

22. O'Neil JT, Wang ML, Kim N, Maltenfort M, llyas AM. Prospective evaluation of opioid consumption after distal radius fracture repair surgery. Am J Orthop (Belle Mead NJ). 2017;46(1):E35.

23. Kim N, Matzon JL, Abboudi J, Jones C, Kirkpatrick W, Leinberry CF, et al. A prospective evaluation of opioid utilization after upper-extremity surgical procedures: identifying consumption patterns and determining prescribing guidelines. J Bone Joint Surg Am. 2016;98(20):e89.

24. Sabatino MJ, Kunkel ST, Ramkumar DB, Keeney BJ, Jevsevar DS. Excess opioid medication and variation in prescribing patterns following common orthopaedic procedures. J Bone Joint Surg Am. 2018;100(3):180.

\section{Publisher's Note}

Springer Nature remains neutral with regard to jurisdictional claims in published maps and institutional affiliations. 